\title{
THE SECOND MADISON COLLOQUIUM
}

The eleventh colloquium of the American Mathematical Society and the second Madison Colloquium was held at Madison, Wis., in conjunction with the thirty-third summer meeting of the Society from September 6-10, 1927, the lecturers being Professor E. T. Bell, California Institute of Technology, and Professor Anna Pell Wheeler, Bryn Mawr College. The first Madison Colloquium was held in 1913, the lecturers being Professors L. E. Dickson and W. F. Osgood.* In opening the colloquium, President Snyder made the observation that this was the first colloquium of the Society at which a woman had been invited to give a course of lectures. Also that geographically the East and West were represented in the speakers, the Middle West in the place of meeting, and the South in a recent addition to the volumes of the colloquium series.

The lectures were divided as is customary into two groups of five lectures each, and were given from Tuesday to Saturday in the auditorium of Sterling Hall. One hundred twenty-seven persons attended these lectures, the largest number registered for any colloquium so far held, though in comparison with the attendance at Ithaca in 1924 (122) the gradient seems to be on the decrease. The names of those attending the lectures follows.

L. K. Adkins, F. E. Allen, Altshiller-Court, W. E. Anderson, Archibald, R. W. Babcock, Barnett, L. Battig, E. R. Beckwith, E. T. Bell, Birkhoff, Blichfeldt, Bray, Brenke, Brink, E. W. Brown, H. E. Buchanan, L. H. Bunyan, Bussey, Cairns, C. C. Camp, Carlson, G. N. Carmichael, R. D. Carmichael, Chang, Chittenden, J. T. Colpitts, Conkwright, C. F. Craig, H. V. Craig, Crathorne, Curry, Dalaker, H. T. Davis, Dean, Dickson, Dines, Dowling, Dresden, J. M. Earl, G. C. Evans, H. P. Evans, Feinler, W. B. Ford, Fry, Gaba, Gergen, Gill, D. C. Gillespie, W. C. Graustein, M. C. Graustein, L. M. Graves, Griffiths, V. G. Grove, Guggenbühl, Harkin, E. Hart, W. L. Hart, Hartung, E. R. Hedrick, Hildebrandt,

* A resume of the first ten colloquia of the Society was given in connection with the report of the second Ithaca Colloquium, this Bulletin, vol. 32 (1926), pp. 25-27. 
Hoersch, Hollcroft, F. Hopkins, Hosford, Hotelling, J. C. Hughes, L. Ingold, Ingraham, D. Jackson, Jensen, Kearney, Kempner, Krathwohl, E. P. Lane, Langer, Latimer, Logsdon, J. V. McKelvey, March, Maria, A. S. Merrill, N. H. Mewaldt, Michal, Mickelson, Miser, E. J. Moulton, Olson, F. W. Owens, H. B. Owens, Palmer, Parkinson, Pettit, Pierce, R. G. D. Richardson, H. L. Rietz, W. C. Risselman, Roever, Roos, Roth, Runge, R. G. Sanger, Shewhart, Shohat, Sinclair, Skinner, Slaught, Slichter, V. Snyder, W. A. Spencer, Stouffer, Swartzel, Tate, J. H. Taylor, E. M. Thomas, Torrey, Trjitzinsky, J. V. Uspensky, Van Vleck, Wall, W. Weaver, Westfall, A. P. Wheeler, Widder, Worthington, Yanney, Yeaton.

Below are given the synopses of the lectures as prepared by the lecturers in the order in which they were given:

\section{ALGEBRAIC ARITHMETIC}

By Professor E. T. BeLL

I. Definition and scope of algebraic arithmetic. Arithmetical theories as opposed to algebraic or analytic. The algebraic varieties useful in arithmetic; irregular fields, rings, rays, semigroups; the algebras of infinite vectors.

II. The algebra of unique factorization. Applications to an arithmetic of functions defined through any unique factorization law.

III. The algebra of parity. Definition of parity functions. Division of parity and equality of functions.

IV. Algebraic arithmetic of multiply periodic functions. Arithmetical identities between arbitrary functions having parity. Applications to theorems on representations of integers in higher forms. Applications to quadratic forms and class number relations. Singly infinite class number relations.

V. Arithmetical structure. Arithmetization of an arithmetizable theory. Solution in terms of symbolic logic of certain of the postulate systems of rational arithmetic.

\section{THE THEORY OF QUADRATIC FORMS IN INFINITELY MANY VARIABLES AND APPLICATIONS}

By Professor Anna Pell Wheeler

I. Spaces of infinitely many dimensions. Vectors. Fundamental quadratic form. Scalar product. Orthogonality. 
Construction of coordinate systems corresponding to a given fundamental form. Properties of coordinate systems in euclidean spaces. Properties of coordinate systems in non-euclidean spaces. Connection between spaces of different types and classes of functions. General coordinate systems.

II. Infinite matrices and linear transformations. Matrices, bilinear forms, and linear transformations. Limitedness with respect to Hilbert space. Limitedness with respect to other spaces. Complete continuity in the Hilbert sense. Extension. Infinite determinants. Some sufficient conditions for the alternative theorems. The Fredholm determinant. Principal solutions of homogeneous equations.

III. Reduction of quadratic and bilinear forms. Nature of invariants of linear transformations in the symmetric case. A necessary condition for the existence of invariants in the symmetric case. Carleman's sufficient condition and extension in the symmetric case. Symmetrizable cases. Semi-symmetrizable cases. Simultaneous reduction of two quadratic forms. Solutions of more general linear equations.

IV. Application to the theory of linear functional equations. Integral equations with continuous symmetric kernels. Integral equations with singular symmetric kernels. Symmetrizable kernels. Semi-symmetrizable kernels. Integrodifferential equations. Systems of integral equations. Linear functional equations of various types.

V. Application to the theory of linear differential equations. Ordinary linear differential equations, orthogonal and polar. Singular linear differential equations. Elliptic differential equations. Hyperbolic differential equations. The Bliss system of differential equations.

Both sets of lectures will be published in book form by the Society. Professor Bell's will appear in the fall of 1927, and Professor Wheeler's probably in 1928.

T. H. HiLdEBRANDT 